\title{
COVID-19, immunoprivilege and structural inequalities
}

\author{
Jordan $\operatorname{Liz}^{1}$ (iD)
}

Received: 15 August 2020 / Accepted: 6 December 2020 / Published online: 10 February 2021 (C) Springer Nature Switzerland AG 2021

\begin{abstract}
As cases of COVID-19 continue to rise, some countries, including the US, Chile, and Germany, have considered issuing "immunity passports." This possibility has raised concerns and debate regarding their potential social, political and economic ramifications, especially for marginalized communities. This paper contributes to that debate by exposing that ways in which immunoprivilege already exists and operates within our present system of structural inequalities.
\end{abstract}

Keywords COVID-19 $\cdot$ Immunoprivilege $\cdot$ Structural inequalities

With cases of COVID-19 rising worldwide, some countries, including the US, Chile, and Germany, have considered issuing "immunity passports," or documentation showing that one has antibodies against the Novel Coronavirus (Mohapatra 2020). ${ }^{1}$ Unsurprisingly, the possibility of such passports has sparked intense debate. Among these, some have argued that immunity passports may give way to a new system of "immunoprivilege." In the name of protecting public health, this system would potentially deny employment and educational opportunities, and even bar entry or use of certain services to those who lack passports. While the prospect of such a system may appear farfetched, there are reasons to be concerned. For example, Qantas, an Australian airline company, has already announced that it will require international travers to submit proof of COVID-19 vaccination before boarding their planes (Hart 2020). Alan Joyce, the CEO of Qantas, expects this restriction

\footnotetext{
1 This note belongs to the Topical Collection "Seeing Clearly Through COVID-19: Current and future questions for the history and philosophy of the life sciences", edited by G. Boniolo and L. Onaga.

Jordan Liz

Jordan.Liz@sjsu.edu

1 San José State University, 201 Faculty Office Building, One Washington Square, San José, CA 95192-0096, USA
} 
to become common practice around the world (Hart 2020). If implemented, it would disproportionately harm the global poor who will likely have limited access to the vaccine. As such, it appears we should take the possibility of future immunoprivilege seriously. I contend, however, that this perspective is flawed. On my view, immunoprivilege already exists, and represents a serious and immediate danger to marginalized groups. To investigate this claim further, I begin by reviewing in more detail the issues raised by immunity passports. Afterwards, I examine the ways in which immunoprivilege already operates within the US, and its impact on marginalized communities throughout the pandemic.

\section{COVID-19 and immunity passports}

Within the literature, there are two prominent objections against the use of immunity passports. First, the biomedical-epidemiological objection that, so far, studies have not proven that prior infection necessarily renders one immune against reinfection. For instance, in a study published in Nature Microbiology, researchers found that those who have tested positive for COVID-19 continued to produce antibodies for approximately six weeks to three months afterwards, depending on the severity of their case (Seow et al. 2020). Meanwhile, other studies have found that, even in the absence of antibodies, certain white blood cells (B cells and T cells) may continue to offer COVID-19 immunity for some time after infection (Cox and Brokstad 2020). Nevertheless, as Natalie Kofler and Françoise Baylis argue, unless this is confirmed, granting immunity passports presents a high-risk public health initiative (Kofler and Baylis 2020). Moreover, even if scientists determine that reinfection is impossible, "tens to hundreds of millions of serological tests would be needed for a national immunity certification programme" (Kofler and Baylis 2020). Not only would that level of testing likely be unfeasible, but serological tests are not entirely reliable. The possibility of false positives and false negatives further complicates the manner. If too many people without antibodies are granted passports, it may lead to more outbreaks if they become infected. Meanwhile, if those with antibodies are denied passports, it may prevent them from accessing social and economic resources.

The latter is intimately tied to the second objection regarding the social and political ramifications of immunity passports. In particular, some scholars, such as Insa Marie Schmidt, argue that these passports may exacerbate existing social inequalities by justifying and even enabling discrimination (Schmidt 2020). It is a system that would benefit the "immunoprivileged" by potentially restricting accessibility to employment, housing, and even where one could shop for essential goods and services. In many ways, it would parallel discrimination against the "unacclimated" in the Deep South during the mid-1800s (Olivarius 2019). During that period, rates of yellow fever were high, and thousands died from it. Those who survived were deemed "acclimated" and given preferential treatment for economic, political, and social opportunities. This system also served to justify further discrimination against immigrants and nonwhites. Indeed, it created a situation wherein marginalized groups would willingly expose themselves to the disease to try to become "acclimated," regardless of whether they had access to healthcare (Olivarius 2019). 
Nevertheless, some scholars have advocated for their use. Rebecca Brown, Julian Savulescu, Bridget Williams, and Dominic Wilkinson argue that such passports may be useful for restoring a sense of normality to many individuals. For example, they would be able to move around more freely, not have to abide by all social distancing guidelines, and even return to work. This, in turn, would have several beneficial social effects, especially by alleviating the economic strain of the pandemic (Brown, Savulescu, Williams and Wilkinson 2020). Similarly, Govind Persad and Ezekiel Emanuel argue that immunity passports may allow us to further protect vulnerable populations by providing safer care. For instance, they suggest that preferential hiring of immune individuals to work at nursing homes or hospitals could help reduce the spread of the virus, while also protecting those most at risk. On their view, preferential treatment for immune individuals does not "violate equal treatment because the factors used to grant a license [or passport] are not discriminatory, like race or religion, but instead grounded in relevant evidence" (Persad and Emanuel 2020). Importantly, despite these endorsements, all of these scholars recognize the need for safeguards to prevent these passports from exacerbating existing inequalities.

\section{Immunoprivilege and structural inequalities}

Such concern is crucial. It is already the case that millions of people within the US (and abroad) suffer the adverse effects of oppressive systems, such as racism, sexism, ableism, classism, homophobia, among many others. Moreover, the fact that many of these prejudices have been medicalized in the past demonstrates all too clearly the ability of scientific knowledge to be leveraged to justify discrimination. In light of that history, it is worth considering a more basic question: does immunoprivilege already exist within the US? I contend that it does - immunoprivilege is already present within the existing framework of structural inequalities. The present pandemic offers us many examples of this. Consider essential workers. With the implementation of shelter-in-place orders, many found themselves either working remotely from home, laid-off or unemployed. The exceptions were those working in essential services, or services deemed vital to the health and welfare of the country.

By and large, essential services are provided by blue-collar labors, who are disproportionately women, low-income, undocumented and/or nonwhite (especially Black and Brown). For example, Hispanics constitute approximately fifty-three percent of agricultural workers; while Blacks compromise thirty percent of licensed and vocational nurses (Washington State Department of Health 2020). One in three jobs held by women are designated as essential services, with women of color being more likely to work an essential job than other demographic (Robertson and Gebeloff 2020). These workers are far more likely to contract the virus, while being far less able to pay for unexpected medical care or even have the option to take a paid sick leave (Centers for Disease Control and Prevent 2020). Importantly, this is immunoprivilege. The privilege of those able to work from home, while others continue the vital work needed to keep the country going - a privilege largely enjoyed by White middle and upper-class men. It is the privilege of remaining gainfully employed while isolating oneself from risk of contagion and death. It is also a 
privilege borne from the long history of segregation and workplace discrimination that consistently relegated marginalized groups to the most hazardous jobs (Seabury, Terp and Boden 2017).

Even the ability to social distance is an immunoprivilege which marginalized groups less frequently enjoy. Most communities of color tend to be densely populated, making social distancing more difficult to practice. Tribal reservations homes and Alaska Native villages, in particular, tend to be more crowded than the rest of the nation (Rodriguez-Lonebear et al. 2020). High unemployment rates for Blacks and Hispanics during the pandemic may lead to greater risk of eviction and homelessness, which may in turn lead to more sharing of housing (Fox 2020). Additionally, because of decades of supermarkets and hospitals not investing in low-income communities, people of color have disproportionately less access to groceries (especially healthy foods) and healthcare. This makes it more difficult, for example, to stock up on enough groceries to stay sheltered-in-place for extended periods. Moreover, because more trips are needed, it prolongs how long one must be outside, potentially exposing themselves (and those they live with) to infection. This is further exacerbated by the overreliance of racial minorities and the poor on public transportation (Center for Disease Control and Prevention 2020). All of these factors create a situation wherein marginalized groups are more likely to contract COVID-19.

Even the environmental conditions faced by people of color pose a serious threat to their health. Across the country, rates of pollutants and toxins are significantly higher in low-income and nonwhite communities (American Lung Association 2020). According to a study by the Union of Concerned Scientists, in California alone, Blacks and Hispanics live in communities with approximately forty percent higher levels of pollution than their White counterparts. Low-income neighborhoods across the state have ten percent higher rates of pollutants than the state average; while pollutants in high-income neighborhoods are thirteen percent below the average (Union of Concerned Scientists 2019). Because of this, such communities tend to have higher rates of respiratory illness such as asthma and lung cancer (American Lung Association 2020). This, in turns, makes them far more susceptible to the harmful effects of COVID-19. The combination of these factors is no accident. They reflect the pernicious effects of longstanding environmental racism and class-based segregation that has conferred among some the immunoprivilege of health, while exposing others to disease and illness.

To be clear, the benefits of immunoprivilege extend beyond the present pandemic. By and large members of marginalized groups are disproportionately more likely to suffer higher rates of chronic illnesses, higher mortality rates and have less access to healthcare (Haynes et al. 2020). As such, regardless of whether or not the US grants immunity passports, immunoprivilege is already present within the US. One's ability to live a long and healthy life is neither a guarantee nor are the chances equal across demographics. Immunoprivilege is simply another in a long list of unacknowledged rewards enjoyed by some at the expense of marginalized Others. COVID-19, far from instituting news forms of discrimination, allows us to see what is already the case - namely, that the health and wellbeing of nonwhite, poor and/or non-male bodies are expendable under the current system ( $\mathrm{Liz}$ 2020). Recognizing the reality of immunoprivilege is essential for addressing 
the disproportionate effects COVID-19 is having on marginalized communities across the country. Until we acknowledge the entire landscape of privileges and hardships maintained by the present system of structural inequalities, the dream of a more equitable and fair society will remain unattainable.

\section{References}

American Lung Association. (2020). Disparities in the Impact of Air Pollution. American Lung Association. https://www.lung.org/clean-air/outdoors/who-is-at-risk/disparities

Brown, R., Savulescu, J., Williams, B., \& Wilkinson, D. (2020). Passport to Freedom? Immunity Passports for COVID-19. Journal of Medical Ethics. https://doi.org/10.1136/medethics-2020106365.

Cox, R., \& Brokstad, K. (2020). Not Just Antibodies: B Cells and T cells Meditate Immunity to COVID-19. Nature Reviews Immunology. https://doi.org/10.1038/s41577-020-00436-4.

Centers for Disease Control and Prevention. (2020). Health Equity Considerations \& Racial \& Ethnic Minority Groups. Centers for Disease Control and Prevention. https://www.cdc.gov/coronaviru s/2019-ncov/need-extra-precautions/racial-ethnic-minorities.html

Fox, M. (2020). Coronavirus Financial Stress is Hitting Blacks and Hispanics Disproportionately, Analysis Finds. CNBC. https://www.cnbc.com/2020/10/15/coronavirus-financial-stress-hitsblacks-and-hispanics-more-than-whites.html

Hart, R. (2020). Qantas Becomes First Airline to Require Passengers to Get COVID-19 Vaccine Before Flying Internationally. Forbes. https://www.forbes.com/sites/roberthart/2020/11/24/qanta s-becomes-first-airline-to-require-passengers-to-get-covid-19-vaccine-before-flying-internatio nally/?sh $=77 \mathrm{~d} 0 \mathrm{f} 6843 \mathrm{df} 2$

Haynes, N., Cooper, L., \& Albert, M. (2020). At the Heart of the Matter: Unmasking and Addressing COVID-19's Toll on Diverse Populations. Circulation. https://doi.org/10.1161/CIRCULATIO NAHA. 120.048126.

Kofler, N. \& Baylis, F. (2020). Ten Reasons Why Immunity Passports are a Bad Idea. Nature. https:// www.nature.com/articles/d41586-020-01451-0

Liz, J. (2020). State racism social justice and the COVID-19 Pandemic. Public Philosophy Journal. https://doi.org/10.25335/ppj.3.1-5.

Mohapatra, S. (2020). Why COVID-19 Immunity Passports May Violate US Law. The Conservation. https://theconversation.com/why-covid-19-immunity-passports-may-violate-us-law-138165

Olivarius, K. (2019). Immunity, Capital, and Power in Antebellum New Orleans. The American Historical Review. https://doi.org/10.1093/ahr/rhz176.

Persad, G., \& Emanuel, E. (2020). The Ethics of COVID-19 Immunity-Based Licenses ("Immunity Passports"). Journal of the American Medical Association. https://doi.org/10.1001/ jama.2020.8102.

Schmidt, I. (2020). Immunity-Based Licenses and the Politics of the Body. Medical Humanities Blog. https://blogs.bmj.com/medical-humanities/2020/08/04/immunity-based-licenses-and-the-polit ics-of-the-body/

Seow, J., Graham, C., Merrick, B., Acors, S., Pickering, S., Steel, K., et al. (2020). Longitudinal observation and decline of neutralizing antibody responses in the three months following SARSCoV-2 infection in humans. Nature Microbiology. https://doi.org/10.1038/s41564-020-00813-8.

Robertson, C \& Gebeloff, R. (2020). How Millions of Women Became the Most Essential Workers in America. The New York Times_https://www.nytimes.com/2020/04/18/us/coronavirus-women -essential-workers.html

Rodriguez-Lonebear, D., Barceló, N., Akee, R., \& Russo, S. (2020). American Indian Reservations and COVID-19: Correlates of Early Infection Rates in the Pandemic. Journal of Public Health Management and Practice. https://doi.org/10.1097/PHH.0000000000001206.

Seabury, S., Terp, S., \& Boden, L. (2017). Racial and ethnic differences in the frequency of workplace injuries and the prevalence of work-related disability. Health Affairs. https://doi.org/10.1377/ hlthaff.2016.1185. 
Union of Concerned Scientists. (2019). Inequitable Exposure to Air Pollution from Vehicles in California. Union of Concerned Scientists. https://www.ucsusa.org/resources/inequitable-exposureair-pollution-vehicles-california-2019

Washington State Department of Health. (2020). We Are All in This Together. Medium. https://mediu m.com/wadepthealth/we-are-all-in-this-together-56860dc707da

Publisher's Note Springer Nature remains neutral with regard to jurisdictional claims in published maps and institutional affiliations. 